\title{
BMJ Global Health Commercial use of evidence in public health policy: a critical assessment of food industry submissions to global- level consultations on non- communicable disease prevention
}

\author{
Kathrin Lauber (D), Darragh McGee, Anna B Gilmore
}

\begin{abstract}
To cite: Lauber K, McGee D, Gilmore AB. Commercial use of evidence in public health policy: a critical assessment of food industry submissions to global-level consultations on non-communicable disease prevention. BMJ Global Health 2021;6:e006176. doi:10.1136/ bmjgh-2021-006176
\end{abstract}

\section{Handling editor Eduardo Gómez}

- Additional supplemental material is published online only. To view, please visit the journal online (http://dx.doi.org/10. 1136/bmjgh-2021-006176).

Received 1 May 2021 Accepted 4 August 2021

A) Check for updates

(C) Author(s) (or their employer(s)) 2021. Re-use permitted under CC BY. Published by BMJ.

Department for Health, University of Bath, Bath, UK

Correspondence to

Kathrin Lauber;

k1580@bath.ac.uk

\section{ABSTRACT}

Background Ultra-processed food industry (UPFI) actors have consistently opposed statutory regulation in health policy debates, including at the WHO. They do so most commonly with claims that regulatory policies do not work, will have negative consequences or that alternatives such as self-regulation work well or better. Underlying this are often assertions that industry is aligned with principles of evidence-based policymaking. In this study, we interrogate if this holds true by exploring the extent and quality of the evidence UPFI respondents employed to support claims around regulatory policy, and how they did this.

Methods First, we identified all submissions from organisations who overtly represent UPFI companies to consultations held by the WHO on non-communicable disease policy between 2016 and 2018. Second, we extracted all relevant factual claims made in these submissions and noted if any evidence was referenced in support. Third, we assessed the quality of evidence using independence from UPFI, nature, and publication route as indicators. Lastly, where peer-reviewed research was cited, we examined if the claims made could be justified by the source cited.

Results Across 26 included consultation responses, factual claims around regulation were made in 18 , although only 10 referenced any evidence at all. Of all 114 claims made, 39 pieces of identifiable evidence were cited in support of 56 claims. Of the 39 distinct pieces of evidence, two-thirds were industry-funded or industrylinked, with only 16 externally peer-reviewed. Over half of industry-funded or industry-linked academic articles failed to declare a conflict of interest (COI). Overall, of only six claims which drew on peer-reviewed and independent research, none appropriately represented the source. Discussion UPFI respondents made far-reaching claims which were rarely supported by high-quality, independent evidence. This indicates that there may be few, if any, benefits from consulting actors with such a clear $\mathrm{COI}$.

\section{INTRODUCTION}

Approximately 10 million global deaths per year are attributable to unhealthy diets, ${ }^{12}$ a

\section{WHAT IS ALREADY KNOWN? \\ $\Rightarrow$ There is growing evidence that regulatory poli- cies are more effective than voluntary industry measures in addressing obesity and dietary non- communicable diseases which pose a growing threat to public health. \\ $\Rightarrow$ Ultra-processed food industry (UPFI) actors claim to be aligned with evidence-based policymaking, but nonetheless consistently oppose evidence-based regulation in favour of voluntary approaches. \\ WHAT ARE THE NEW FINDINGS? \\ $\Rightarrow$ Our research shows that, in response to WHO con- sultations, UPFI groups made many factual claims to oppose regulatory policies and promote alternative measures, but only cited evidence in support of just over half of all instances. \\ $\Rightarrow$ Most respondents did not make extensive use of evidence. \\ $\Rightarrow$ The majority of the evidence cited to support factual claims lacked key indicators of quality such as inde- pendence or external peer review. \\ $\Rightarrow$ Where industry respondents cited peer-reviewed re- search evidence, they often failed to represent the source accurately.}

key risk factor for non-communicable diseases (NCDs) such as cancers, cardiovascular disease, and type 2 diabetes. ${ }^{3}$ Over recent decades, it has become increasingly evident that industry self-regulation is less effective to improve diets than government regulation. ${ }^{4-16}$ Yet, and despite sustained calls by the public health community for comprehensive regulatory frameworks to safeguard children's right to health in particular, ${ }^{17-20}$ such policies remain sporadic. This disconnect reflects the significant role played by politics, values, ideas and discourse, as well as the notion that all evidence is socially constructed, ${ }^{21}$ contestable and open to interpretation. ${ }^{22-24}$ 


\section{WHAT DO THE NEW FINDINGS IMPLY?}

$\Rightarrow$ In line with previous research on commercial use of evidence, our study suggests that UPFI actors not only tend to provide evidence which lacks key quality indicators but also employ evidential practices which serve to create doubt about the public health evidence.

$\Rightarrow$ As such, industry actors might not only feed lower-quality evidence into policy processes; mirroring discourse around science and evidence could also potentially bolster their credibility and that of their arguments.

$\Rightarrow$ Thus, those developing public health policies or policy recommendations should reconsider if and how they engage with commercial actors.

Narrow conceptions of evidence-based policymaking (EBPM) largely fail to account for this real-world context in which evidence and policy are created.$^{25}$ The alternative term evidence-informed policymaking has emerged more recently, explicitly acknowledging that while the best available evidence should be used, decisions are not purely based on technical considerations. ${ }^{26}$ Regardless of differences in terminology, it is clear that efforts to improve the uptake of knowledge in public health policy over recent decades have firmly positioned evidence as a source of power and legitimacy in decision-making. ${ }^{25} 27$ Crucially, this goes beyond the instrumental power of evidence and its producers or users, extending to the discursive power actors can derive from claims to scientific knowledge and authority.

The fundamentally political nature of policymaking is particularly noticeable where powerful commercial entities find themselves facing a threat of regulation: multinational companies involved in the sale of ultra-processed food and beverage products as well as their representative groups (the ultra-processed food industry, UPFI) have consistently engaged in 'corporate political activity' to prevent, delay, or weaken regulatory policies, ${ }^{28-34}$ which has been identified as a key barrier to effective dietary public health policy. ${ }^{35}{ }^{36}$ Large volumes of research on the tobacco industry ${ }^{37-40}$ and now increasingly on the $\mathrm{UPFI}^{30} 3241-45$ and other unhealthy commodity industries $^{46-49}$ show that corporate actors' ability to shape and use evidence in their own interest plays a key part in their policy-influencing strategies. ${ }^{50}$

Even preceding an acute policy debate, corporate influence on science can shape the body of evidence on a topic, thereby influencing what is perceived as a problem and which solutions are considered. Research funded by UPFI entities or conducted by academics with a conflict of interest (COI) appears more likely to reach conclusions that are favourable or simply non-threathening to the donor industry. ${ }^{51-55}$ Systematic reviews where authors declared a COI, for instance, were found to be five times more likely to conclude no positive association between sugar-sweetened beverage (SSB) consumption and weight gain than independent reviews. ${ }^{53}$

On the other hand, a less studied facet of the interface between public health policy, evidence, and corporations is the strategic use of evidence within the policymaking process. Existing public health research on this topic has focused predominantly on tobacco control ${ }^{56-58}$ and alcohol policy, ${ }^{59-61}$ with only two articles, to our knowledge, systematically exploring use of evidence within dietary NCD policy. ${ }^{28}{ }^{62}$ Largely divisible into two analytical strands, examinations of the nature of evidence used by commercial actors and of how this evidence or, more broadly, the concept of evidence are used. The available research suggests that unhealthy commodity industry actors predominantly use evidence that is not independent and externally peer-reviewed-thus lower in quality - and where they do use scientific evidence, tend to misrepresent the source. $.^{28} 56-586062$

This paper aims to combine both of these analytical strands to explore how UPFI actors promote their NCD policy preferences at the WHO. It builds on a previous study where we document how UPFI associations opposed regulatory approaches such as marketing restrictions, mandatory front-of-pack labelling, and particularly SSB taxation in consultations held to inform WHO recommendations. ${ }^{63}$ At their core, claims focused on conveying the narrative that regulatory policies would not have the desired public health effect, would lead to unintended negative consequences, and that alternatives to regulation would be equally or more effective. In line with earlier research, ${ }^{30} 4364$ we showed that UPFI actors widely espoused the concept of EBPM and made prominent use of terms related to science and evidence to justify opposition to regulatory approaches. In light of these industry claims to take an evidence-based approach, we aim to investigate whether and how evidence was used to support factual claims about regulation in recent WHO consultations. Specifically, we ask:

1. To what extent did UPFI actors refer to evidence when making factual claims about policies?

2. What types of evidence did UPFI actors refer to when making factual claims about policies? Was it independent and peer-reviewed?

3. Where peer-reviewed research was cited to support factual claims, does the claim accurately reflect the source content?

To address the last research question, we draw on concepts from agnotology, a term coined by Proctor ${ }^{65}$ to describe the study of the deliberate spread of ignorance, which posits that policymaking may be shaped by so-called agnogenic practices, 'methods of representing, communicating, and producing scientific research and evidence which work to create ignorance or doubt irrespective of the strength of the underlying evidence' ${ }^{62}$ Previous research exploring agnogenic practices in consultations for UK tobacco plain packaging ${ }^{58}$ and the South African SSB $\operatorname{tax}^{62}$ found that corporate actors used techniques such as quoting evidence in misleading ways, mimicking scientific critique to contest the public health evidence supporting regulation, and excluding relevant evidence while promoting alternative narratives. 


\section{METHODS}

To explore how evidence has been used by commercial actors in global-level policy spaces, we analysed UPFI responses to WHO consultations on NCD policy. Specifically, we focused on arguments against the statutory regulation of unhealthy foods and non-alcoholic beverages, assessing the evidence cited in this context for markers of quality. To establish whether peer-reviewed evidence was represented accurately, we also conducted a verificationoriented cross-documentary analysis which compares claims made with the cited source documents. ${ }^{5862}$

\section{Data}

We systematically searched the WHO Headquarters website for consultations held between 2016 and 2018 which covered dietary NCD policy, were global in scope, and for which all responses were published in full. Four consultations met our criteria: the web-based consultation of the WHO Independent High-level Commission on NCDs, ${ }^{66}$ the consultation on the Member State-led draft outcome document for the WHO Global Conference on NCDs ("Montevideo roadmap'), ${ }^{67}$ and the consultations on updating Appendix 3 of the WHO Global NCD Action Plan 2013-202068 and the zero draft Shanghai Declaration on Health Promotion. ${ }^{69}$ The consultations are described in more detail elsewhere. ${ }^{63}$ From the 393 total responses to these consultations, we extracted all responses made on behalf of the UPFI, starting with all private sector submissions (as categorised by $\mathrm{WHO}$ ) to identify submissions overtly representing the UPFI (ie, corporations manufacturing ultra-processed foods/soft drinks or holding a financial interest in their sale, or business associations who self-describe as representing the latter). Of the identified 33 responses from UPFI actors-all business associations-we excluded six which were not in English ${ }^{70-75}$ and one which contained only a copy of the consultation document, ${ }^{76}$ leaving 26 submissions.

\section{Identification of factual claims and evidence used to support} them

Our analysis concentrated on statements which opposed regulatory approaches to dietary NCDs, as we could not identify any which supported the introduction of new statutory regulation. Using Atlas.ti ${ }^{77}$ software, the lead author coded all instances within the 26 included submissions where factual claims-defined as statements which appear to convey a fact rather than a belief, opinion, or idea-were made in relation to policy effects. Thus, statements which merely referred to the existence of policies or commitments without discussing their effects were not included. Factual claims were coded into three core categories and two subcategories which we developed after in-depth reading of the documents (table 1). Where a sentence made more than one of the assertions below, these were counted as two separate claims.

Next, we coded whether any evidence was referenced in support of the claim, and extracted it into a spreadsheet. We adopted a broad definition of evidence as formal and informal written sources, such as reports, journal articles, press coverage, blogs, and opinion pieces. We included all instances where evidence was formally cited (at the end of a page or submission), or referred to in the text, provided enough information was available to identify it through a web search. Links to general websites were not included as they do not clearly refer to a distinct piece of evidence. Where coding decisions were challenging or uncertain, this was resolved in discussion between the first and second author.

\section{Analysis}

We conducted two separate analyses. First, we assessed the quality of all evidence referenced in support of factual claims on policy effects. Second, we assessed how peerreviewed research was used in this context.

Table 1 Categorisation framework for factual claims

\begin{tabular}{ll}
\hline Factual claim category & Detail \\
\hline $\begin{array}{l}\text { 1: Regulation does not } \\
\text { work }\end{array}$ & $\begin{array}{l}\text { Claims that statutory approaches to regulating unhealthy products, in particular SSB taxes, do not } \\
\text { have the intended benefits for public health, arguing that a policy will fail or has previously failed to } \\
\text { reduce consumption of the target products. }\end{array}$ \\
$\begin{array}{l}\text { 1.1: The rationale for } \\
\text { regulation is flawed }\end{array}$ & $\begin{array}{l}\text { Claims which do not directly refer to policy effects, but question the causal mechanisms } \\
\text { underlying obesity and dietary NCDs which regulatory approaches seek to tackle, for instance, the } \\
\text { link between obesity and/or NCDs and the target products. }\end{array}$ \\
\hline $\begin{array}{l}\text { 2: Regulation will have } \\
\text { unintended negative } \\
\text { consequences }\end{array}$ & $\begin{array}{l}\text { Some respondents went further to suggest that regulatory policies may have negative economic } \\
\text { consequences or will even be counterproductive, for instance, increasing the consumption of } \\
\text { other unhealthy products. }\end{array}$ \\
\hline $\begin{array}{l}\text { 3: Alternatives to } \\
\text { regulation work well/better }\end{array}$ & $\begin{array}{l}\text { Claims that alternatives to regulation-information campaigns, self-regulation or co-regulation- } \\
\text { an important pillar of a broader argument that regulatory policies are not needed. }\end{array}$ \\
\hline $\begin{array}{l}\text { 3.1: Compliance with self- } \\
\text { regulation or co-regulation } \\
\text { is high }\end{array}$ & $\begin{array}{l}\text { Statements suggesting that industry compliance with self-regulation or co-regulation is high, thus } \\
\text { implying positive effects without directly referring to public health outcomes. }\end{array}$ \\
\hline
\end{tabular}

NCDs, non-communicable diseases; SSB, sugar-sweetened beverage. 


\section{Analysis of evidential quality}

We adopted the criteria from Evans-Reeves $e t a l^{8}$ and Hatchard $e t a l^{56}$ to assess the quality of evidence referenced: independence from the UPFI, nature of evidence and publication route (see table 2 for detail). Independence was assessed by first searching if the consultation submission itself stated a link between an UPFI entity and the evidence cited. If this was not the case, we went on to screen the cited piece of evidence for a funding or conflict or interest statement. If none was declared, we conducted web searches for the authors in combination with the name of the organisation which cited the evidence in its consultation response, and the four largest packaged food and soft drink companies (The Coca-Cola Company, PepsiCo, Nestlé, Mondelez). ${ }^{79} 80$ This sample was selected because large corporations have been found to be more involved in funding nutrition research compared with smaller companies and trade associations. ${ }^{55}$ We also read author curriculum vitaes and short biographies where available. Evidence was classified as clearly independent if it was published by an intergovernmental organisation or government, or if clear funding or COI statements were available and did not list any recent (<6years) UPFI financial links, and web searches did not reveal any UPFI connections. The nature of evidence was categorised as research, opinion, strategy documents or raw data. To assess the origins of evidence, we categorised the publication route as either peer-reviewed journals and other academic outlets, intergovernmental organisations and governments, or publications by private companies and organisations. We separately assessed if academic sources had been externally peer-reviewed. For industryfunded and industry-linked academic publications, we also noted whether the source declared a COI. We ran descriptive analyses in IBM SPSS version $26 .{ }^{81}$

\section{Analysis of use of scientific evidence}

To examine how scientific evidence was used by industry actors, a verification-oriented cross-documentary analysis was conducted for all instances where peer-reviewed research articles were cited to support relevant factual claims. In each case, we compared the statement made with the cited source to assess whether the claim reflected the latter. During this process, we noted where agnogenic practices occurred, drawing on the typology developed by Ulucanlar et $a \tilde{l}^{5}$ based on an analysis of tobacco industry misuse of scientific evidence (table 3 ).

\section{RESULTS}

\section{Factual claims and evidence used to support them}

UPFI actors made 114 separate factual claims in 18 of the 26 included submissions (figure 1). Of these 114 claims, 66 challenged regulatory policies (claim categories $1,1.1,2)$ and 48 supported alternative policies such as self-regulation or co-regulation (claim categories 3, 3.1). With the exception of two claims related to advertising, all claims countering regulatory policies focused on fiscal policy. The promotion of alternatives to regulation spanned across a wide range of measures such as voluntary reformulation and labelling, advertising codes and public-private partnerships.

Only 71 of the 114 claims in 10 of the 26 responses actually referred to any evidence. Yet, only in 56 of the 71 factual claims citing evidence was this evidence identifiable: the remaining lacked key information such as title, year published, or author, and one item was paywalled market research data.

The remaining 43 factual claims were made without any reference to a specific piece of evidence, despite some making strong statements with casual references to 'the evidence', as exemplified by the Italian business association Federalimentare ${ }^{82}$ which asserted that

[a]vailable scientific evidence on sugar does not support a causal link between sugars consumption and obesity and associated chronic disease. As an example, while sugar consumption decreased in UK, Australia and Canada, the obesity rate grew in their respective populations.

Similarly, the International Food and Beverage Alliance (IFBA) ${ }^{83}$ claimed, without providing evidence in support, that

[...] the UK salt reduction initiative, a public-private partnership led by the UK government which has resulted in the reduction of average daily salt intakes by $15 \%$ since 2001. Similar salt reduction initiatives and trans fat and calorie reduction strategies around the world have also proven effective.

The 56 claims with identifiable references were made by only five business associations: the International Council of Beverages Associations (ICBA), IFBA, the Grocery Manufacturers Association (now Consumer Brands Association), ${ }^{84}$ Food Industry Asia and the German Federation for Food Law and Food Science (now Food Federation Germany). ${ }^{85}$ The majority of these claims were made by ICBA who participated in three of the four included consultations.

\section{Quality of evidence}

The 56 claims citing identifiable evidence referred to 39 separate pieces of evidence. Figure 2 summarises overall findings on quality of evidence, showing that although a significant proportion of the evidence cited was research published in higher-quality outlets (academic journals, governmental/international organisations), the majority was neither independent nor peer-reviewed. Only four cited items were independent, peer-reviewed research.

\section{Independence}

Of these 39 pieces of evidence, just nine $(23.1 \%)$ were clearly independent, while $13(33.3 \%)$ were industryfunded; 13 (33.3\%) were industry-linked, four (10.3\%) appeared independent but did not provide sufficient information to conclusively rule out industry links. In most pieces of evidence classified as industry-linked, one or more of the authors had received funding from UPFI 


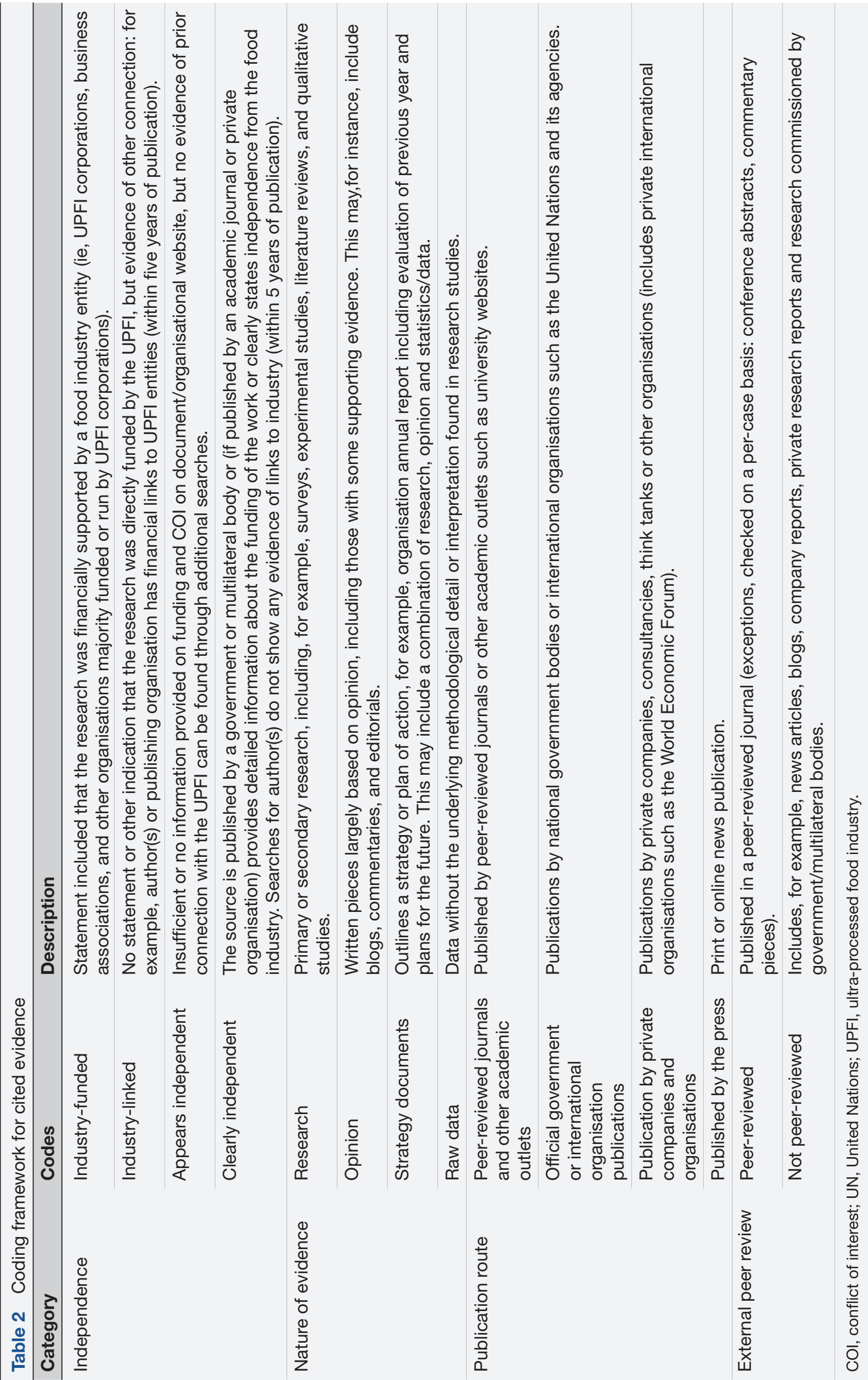

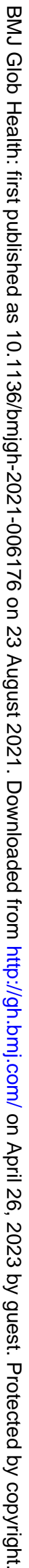


Table 3 Analytical framework for use of scientific evidence, adapted from Ulucanlar et al's evidential strategies ${ }^{58}$

\begin{tabular}{ll}
\hline Industry practice & Description \\
\hline $\begin{array}{l}\text { Misleading quoting of } \\
\text { evidence }\end{array}$ & $\begin{array}{l}\text { Inaccurate reporting from published scientific research, including misquoting, selective } \\
\text { quoting or misinterpretation. }\end{array}$ \\
\hline Mimicked scientific critique & $\begin{array}{l}\text { Detailed inspection of published research, superficially resembling scientific peer review and } \\
\text { using scientific terminology. For instance, seeking methodological perfection or insisting on } \\
\text { methodological uniformity. }\end{array}$ \\
\hline Evidential landscaping & The promotion of alternative evidence or exclusion of relevant public health evidence.
\end{tabular}

entities (see online supplemental file 1 for details). In particular, claims supporting alternatives to regulation (categories 2 and 3)-most often self-regulatory initiatives-heavily relied on evidence that was not independent ( $75 \%$ industry-linked/funded). This encompassed predominantly industry-conducted or commissioned evaluations of their own commitments.

Of the 13 items of industry-funded or industry-linked evidence which were published in academic journals, only four clearly declared a COI. ${ }^{86-89}$ An additional two reported industry financial contributions, but did so under 'acknowledgements' or 'acknowledgements and disclosures' ${ }^{90} 91$ Of the rest, four did not have a COI section, ${ }^{92-95}$ while three articles explicitly declared no COI, ${ }^{96-98}$ one thereof not only linked to, but funded by an UPFI entity. ${ }^{96}$

\section{Nature of evidence}

Of the 39 pieces of evidence, $26(66.7 \%)$ were research, eight $(20.5 \%)$ were strategy documents, four $(10.3 \%)$ were opinion pieces, and one $(2.6 \%)$ was raw data. Notably, 19 of the 26 research-based sources were industry-funded or -linked.

\section{Publication route}

Of the 39 pieces of evidence, 18 (46.2\%) were published by academic outlets, closely followed by private companies and organisations which had published 17 (43.6\%). This included reports published by the submitting business associations themselves and evidence from think tanks and research firms such as Oxford Economics ${ }^{99} 100$ and McKinsey Global Institute. ${ }^{101}$ 'Overcoming obesity: An initial economic analysis' by the McKinsey Global Institute was also the most referenced piece of evidence across all submissions, cited nine times across five consultation responses by three different business associations. A further four items $(10.3 \%)$ were published by intergovernmental organisations or governments. Only 16 (41\%) pieces of evidence cited to support factual claims were externally peer-reviewed. This is less than the number of items published in peer-reviewed journals, as two referenced conference abstracts do not appear to have undergone external peer review. ${ }^{89}$

\section{Use of scientific evidence}

In this section, we address how scientific evidence was used to support the factual claims around policy effects. We discuss examples under each core category of claims: questioning regulatory policies (claim categories 1, 1.1, and 2) and promoting alternatives to regulation (claim categories 3 and 3.1).

\section{Questioning regulatory policies}

Factual claims that regulatory policies do not work or will have negative consequences, although made in 12 responses from seven organisations, were only backed by peer-reviewed research evidence in three responses, all made by one organisation, ICBA. They cited three independent research articles to support five claims that SSB taxation does not work or will have negative consequences, ${ }^{102-104}$ and a fourth to question the link between SSBs and obesity. ${ }^{105}$

Evidence used (identifiable, accessible) No evidence used No identifiable evidence used No accessible evidence used

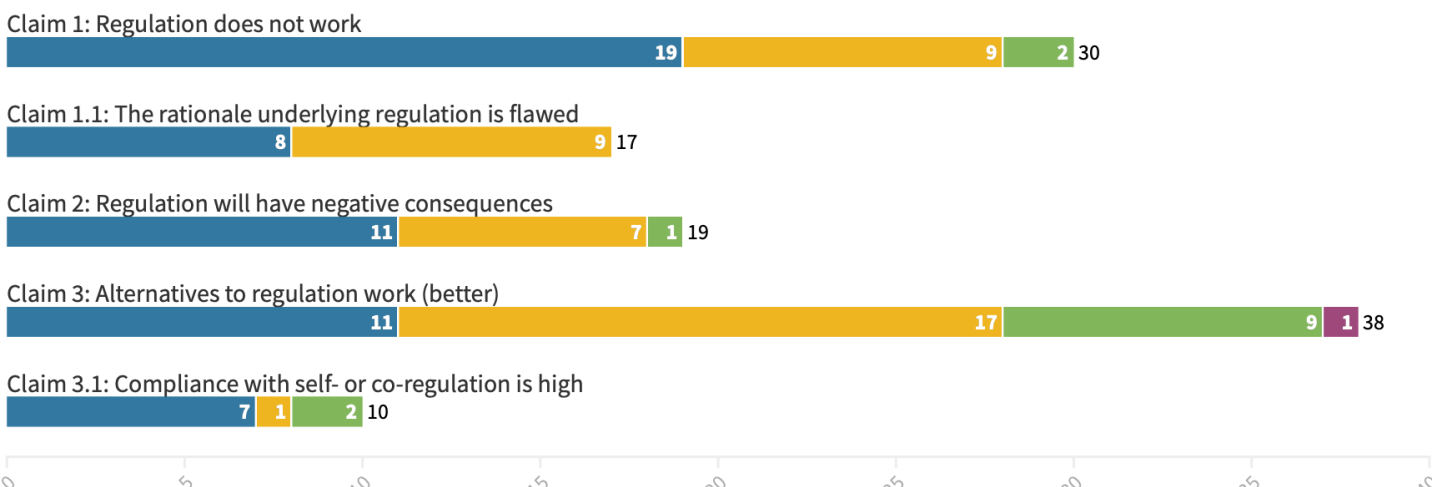

Figure 1 Evidence used to support different types of claims. Created using flourish studio. ${ }^{81}$ 
Higher quality Lower quality

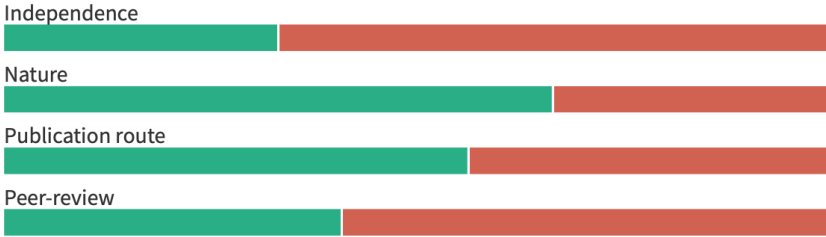

Figure 2 Quality indicators across all 39 pieces of evidence cited to support factual claims. Higher quality was indicated where evidence was clearly independent or appeared independent, was based on research, published in a peerreviewed journal or by a government/intergovernmental organisation, and was externally peer-reviewed. Created using flourish studio. ${ }^{81}$

To question the effectiveness of the policy, they cited a review by independent scientists, Bes-Rastrollo et $a l^{102}$ in their submission to the consultation on Appendix 3 to WHO Global NCD Action Plan 2013-2020, ${ }^{106}$ stating that a

recent review summarizing all data related to taxation of sugars found that taxation did not affect obesity rates [reference: Bes-Rastrollo $e t a l$. In this summary, it was found that of the six published studies to date where data had been measured (as opposed to modeled), five found no effect of taxation whatsoever, while the sixth found less than a $1.8 \mathrm{~kg}$ difference in body weight after 20 years.

This appears to reflect a technique Ulucanlar et a ${ }^{\tilde{8}}$ term misquoting of evidence, as the original source concludes that the "best available scientific evidence suggests that added sugars, especially SSB consumption, are an important risk factor for weight gain and obesity' and that the 'tax tool alone on added sugars appears insufficient to curb the obesity epidemic, but it needs to be included in a multicomponent and comprehensive structural strategy to combat obesity'. ${ }^{102}$ While the second part of ICBA's statement, focusing on observation studies, is accurate, it omits important contextual information, first that most tax rates in the observational sample were lower than the recommended $20 \%$ threshold, as remarked by Bes-Rastrollo et al themselves, and second, that overall, 'results found a significant inverse association between SSB excise taxes and weight gain or obesity, although the magnitude of the estimates of effect was small'. ${ }^{102}$

In their submission to the WHO Independent HighLevel Commission on NCDs and a similar comment on the Montevideo Roadmap 2018-2030, ICBA selectively quoted a publication by Silver et $a l^{104}$ to support an argument that SSB taxation would not only fail to reduce SSB consumption but would also increase the consumption of other unhealthy products:

In Berkeley, California, a tax on SSBs has caused calorie intake to rise rather than decrease. For instance, a recent study of the SSB tax implemented in Berkeley, California, found that while caloric consumption of taxed beverages dropped by a statistically insignificant margin of an average of six calories per day - equivalent to a bite of an apple, caloric consumption of untaxed beverages rose by an average of 32 calories per day, resulting in a net increase of 26 calories per person per day resulting from the tax [reference: Silver et al]. In other words, consumers switched from soft drinks to milkshakes, smoothies and other similarly calorie-dense products - resulting in more calories consumed.

In fact, Silver et alconcluded that one year after the introduction of the Berkeley SSB tax, "prices of SSBs increased in many, but not all, settings, SSB sales declined, and sales of untaxed beverages (especially water) and overall study beverages rose in Berkeley'. ${ }^{104}$ The figure reported by ICBA only refers to the self-reported SSB intake which decreased by $19.8 \%$ but was statistically insignificant. The authors reported statistically significant results for an increase of $15.6 \%$ in water sales and a $9.6 \%$ decrease in SSB sales. Self-reports did indicate an increase in caloric intake of untaxed beverages such as milkshakes and yoghurt smoothies, but ICBA failed to address the authors' observation that this contrasts with the substitution pattern seen in the "point-of-sale data, which showed an increase in water sales and smaller but still significant increases in sales of plain milk and untaxed fruit, vegetable, and tea drinks'. 104

Discussing an independent observational study by Colchero et $a l^{103}$ on changes in purchasing after the introduction of an SSB tax in Mexico in their submission to the WHO consultation on Appendix 3 of the Global NCD Action Plan, ${ }^{106}$ ICBA omitted important qualifying information to suggest that the study demonstrates the ineffectiveness of the policy:

Although one widely-publicized study indicates that purchases of taxed beverages decreased by an average of six percent in 2014 [reference: Colchero et al], it is important to note that the calorie consumption from beverages has declined only slightly - roughly between two and six fewer calories per day in a diet of more than 3000 calories per day in Mexico [reference: FAO, National Institute of Statistics and Geography, and National Association of Soft Drink and Carbonated Water Producers], which is a daily caloric decrease of less than one half of one percent.

Although the $6 \%$ average figure is correct, ICBA failed to mention that the decline in consumption had grown progressively, reaching $12 \%$ by the end of 2014 . Moreover, in a footnote, ICBA also appeared to mimic scientific critique by insisting on methodological perfectionism, pointing out ostensible methodological flaws to dismiss Colchero $e t a l$ s findings:

This study had a number of methodological and other limitations. For example: (1) it was an observational study so causality could not be established; (2) rural populations were ignored and traditional stores [...] were likely underrepresented (as were the working poor or very poor) since the study was based on Nielsen panel data covering 53 cities each with 50,000 or more residents; (3) the data was based on purchases and not consumption; and (4) the study was not controlled for other environmental factors 
(eg, information campaigns that could have had a bigger impact than the actual tax).

It is noteworthy that ICBA directed no such critical assessment towards the favourable, typically lower-quality evidence it cited throughout this submission.

ICBA invoked six articles to question the wellestablished ${ }^{107}$ link between sugar or SSBs and obesity or negative health outcomes. Five of these were either industry-funded or industry-linked ${ }^{86-889091}$ The sixth, independent study, ${ }^{105}$ was cited correctly to the extent that ICBA echoed the authors' finding that the evidence on the relationship between SSB consumption and body mass index is mixed if adjusted for total calorie intake. However, a preceding claim by ICBA that 'the overall weight of the scientific evidence on sugar and/or sugarsweetened beverages show [sic] that they do not have a unique effect on body weight beyond their contribution to total calorie intake' is not supported by the article which states that its conflicting results, while potentially weakening confidence in association strength, do not disprove an association between SSBs and obesity. This also appears to be a misquotation of evidence. ${ }^{58}$

\section{Promoting alternatives to regulation}

IFBA and the Grocery Manufacturers Association were the only organisations to use peer-reviewed research articles in support of self-regulation or co-regulation. They did so in eight instances, and all articles were either industry-funded or industrylinked. ${ }^{93-97}$

IFBA ${ }^{83}$ for instance, used two academic publications ${ }^{95}{ }^{97}$ to support its statement that EPODE (Ensemble Prévenons l'Obésité Des Enfants), a public-private programme partly funded by companies such as Nestlé and The Coca-Cola Company, ${ }^{108}$ 'has shown encouraging results in preventing childhood obesity in France and Belgium and has reduced the socioeconomic gap in obesity prevalence in France'. The first paper by Van Koperen $e t a l^{7}$-which we classified as industry-linked because there was evidence that two of the authors had accepted UPFI funding in the fiveyears before publication-did not set out to examine the effectiveness of EPODE, but to "learn more on the dynamics and key elements of the EPODE program tackling childhood overweight and obesity to support future research and evaluation' and present a logic model ${ }^{97}$ Similarly, the second paper, ${ }^{95}$ which was supported by The Coca-Cola Company and whose lead author also contributed to the Van Koperen et al article, aimed to "provide a detailed description of EPODE methodology, including its broad and overarching approach to strengthening and enriching CBIs [community-based interventions] aimed at preventing childhood obesity'. ${ }^{95}$ The article does, however, suggest that decreases in obesity prevalence in EPODE pilot towns are attributable to the programme, with IFBA repeating a statement made in the article's abstract that EPODE has 'shown encouraging results in preventing childhood obesity in France and Belgium and has reduced the socioeconomic gap in obesity prevalence in France'. ${ }^{95}$

\section{DISCUSSION}

By exploring UPFI use of evidence in global health governance for the first time, we add to an emerging body of literature investigating how unhealthy commodity industries use evidence to oppose public health regulation. ${ }^{57-59} 62$ In summary, our work indicates that the factual claims UPFI actors made to oppose the regulation of unhealthy products in consultation with the WHO were largely unsupported by high-quality, independent evidence, and where scientific evidence was used, it was often misrepresented.

It is noteworthy that, despite claims to support EBPM and language which mimics scientific reasoning, ${ }^{63}$ over half of the UPFI submissions we analysed did not refer to any evidence. Even among those which did, a significant proportion of claims opposing dietary public health regulation were not supported with any evidence. Where evidence was cited, the majority was neither peerreviewed nor independent: of 114 factual claims, only 6 were made based on peer-reviewed and independent research, all of which misrepresented the original source to some degree. These six claims were all made by the same organisation, ICBA, to oppose SSB taxation. The group, which represents soft drinks producers, submitted some of the longest consultation responses with the most references to evidence, which goes a long way towards explaining the skew of our sample towards SSB taxation.

Overall, the arguments made by UPFI respondents to oppose statutory regulation do not align with the public health evidence. Claims that regulation to address dietary NCDs does not have the desired effect, predominantly levelled at SSB taxation, contradict independent evidence which supports the potential of taxes to favourably influence dietary behaviours. ${ }^{109-112}$ Although the evidence in favour of SSB taxes has grown substantially since the consultations were held, high-quality publications were available when the majority of consultation submissions were written. ${ }^{113}$ UPFI respondents also questioned the links between their products or specific ingredients-predominantly sugar-and obesity or dietary NCD, despite a substantial body of independent evidence which links added sugar intake, ${ }^{114}$ and SSBs in particular, ${ }^{115-117}$ to obesity and a range of NCDs. Similarly, claims of negative economic consequences were primarily made in the context of SSB taxation. While industry-commissioned evidence does tend to report such impacts, ${ }^{118}$ independent research suggests that SBB taxes have not had negative impacts on employment and the wider economy, ${ }^{118-121}$ or even businesses. ${ }^{112}$ Initial evidence suggests that other regulatory policies which were contested by industry-mandatory labelling and advertising restrictions-also work as intended ${ }^{122} 123$ and do not affect employment. ${ }^{124}$ 
Independent evidence also indicates that self-regulation is not sufficient to address the issues of obesity and dietary NCDs. ${ }^{4-12}$ Self-regulation of advertising, for instance, does not appear to be effective enough to reduce children's exposure to unhealthy food adverts ${ }^{68125-128}$ and industry codes have widely been criticised as weak by public health researchers. ${ }^{6129}$ In line with evidence which suggests that industry-funded research results in more favourable conclusions, ${ }^{51-55}$ industry evaluations of self-regulatory codes tend to report much higher effectiveness and compliance than independent evaluations. ${ }^{128}$ This may explain our observation that the vast majority of claims in favour of self-regulatory or co-regulatory approaches relied on industry-produced or industry-commissioned materials.

When assessing the independence of cited evidence, we found it remarkable that the majority of industryfunded or industry-linked academic articles did not declare a COI. While some simply did not contain a COI section, others explicitly declared that they had no COI. Of those that did declare an interest, this was at times combined with the acknowledgements. This exemplifies why current reporting practices are inadequate and highlights the urgent need for enforced and structured COI reporting processes within and beyond public health. ${ }^{130}$

There are indications that commercial actors draw on a shared set of preferred evidence and consultancies across levels of governance and policy settings. For instance, reports by the research firm Oxford Economics ${ }^{9100}$ an organisation with a history of producing reports for the tobacco industry ${ }^{131}$-were also cited by respondents to the South African SSB tax consultation. ${ }^{62}$ The most frequently cited item in our study, a discussion paper funded and written by the McKinsey Global Institute ${ }^{101}$ which ranks taxation and media restrictions as low-impact interventions to address obesity, but concludes that only comprehensive measures will work to tackle obesity, has also been cited in other policy debates to oppose public health regulation. ${ }^{64132}$

In addition to the agnogenic practices described above, casual mentions of 'the evidence' or 'science' without reference to concrete evidence, as well as vague expressions of alignment with EBPM, appear to form part of attempts to position industry as a legitimate actor in public health policy. Sitting beyond the instrumental role of evidence, this rhetorical facet may play a role in lending discursive power and credibility to policy actors.

Overall, our findings confirm existing research on the use of evidence by unhealthy commodity industries in public health policy, ${ }^{59-61} 133$ adding to a growing body of literature which indicates high levels of coherence in practices across sectors. ${ }^{134-137}$ This warrants reconsideration of engagement with actors who hold a clear commercial interest in a deregulated food system, perhaps towards an approach more coherent with Article 5.3 of the WHO Framework Convention on Tobacco Control which demands that public health policymaking is protected from the vested interests of the tobacco industry. ${ }^{138}$ Where engagement does take place, adjustments to consultation processes could be made, both to encourage the use of higher-quality evidence (and recognition were there is none) and to enable those developing policies or policy recommendations to more readily assess cited sources. One way to achieve this may be to require consultation respondents to declare origins and funding of referenced evidence, particularly where the submitting organisation itself has financially supported the research or researchers. Consultation documents may also ask respondents to provide evidence in support of their claims in a structured way and directly attach sources where these are not publicly available, thus facilitating evidence appraisal by policymakers.

\section{Limitations}

Our results on evidence use were heavily driven by a small set of actors who referenced large amounts of evidence, whereas the majority referenced little or no evidence. This may limit their generalisability of our findings. While we went beyond declarations in the cited sources to identify industry links to the evidence, our web-based investigation is unlikely to have identified all extant connections. Our research focused on UPFI actors and does not compare how non-industry actors such as Member States or civil society used evidence in their submissions. We concentrated on this subset of respondents due to the inherent conflict between the interests of the UPFI and public health, which has manifested in UPFI opposition to policies needed to address the considerable burden of obesity and NCDs. ${ }^{3463139}$

\section{CONCLUSIONS}

Our findings suggest that UPFI actors' rhetorical alignment with $\mathrm{EBPM}^{63}$ remains mere rhetoric in a majority of cases. Stakeholder consultation, while potentially valuable in that it allows communities and civil society to feed into policy documents, also explicitly gives a voice to the often better-resourced industries whose products are at threat of being regulated. This becomes an issue when-as shown in this study-industry actors question the benefits and emphasise the costs of public health regulation while supporting their preferred alternatives, largely by promoting low-quality evidence or misrepresenting higher-quality evidence. Thus, it is important to critically evaluate the claims made and evidence used in consultation submissions, a process which is timeconsuming and would pose a substantial burden on policymakers. On a practical level, this might be eased through clear reporting requirements and thresholds regarding the quality and independence of evidence. This does not, however, address the less tangible but potentially powerful gain of legitimacy which commercial actors may achieve by aligning themselves with the ideal of EBPM. In light of similar conduct of other unhealthy commodity industries, it is worth questioning the value engagement with commercial interests adds to policy 
development. This is particularly pertinent as resources could instead be invested into redressing power asymmetries in global health governance, for instance, by more actively involving less politically powerful parts of the food system.

Twitter Kathrin Lauber @kathrin_lauber and Darragh McGee @DrDarraghMcGee

Contributors $\mathrm{KL}$ planned the study with guidance from $\mathrm{ABG}$ and $\mathrm{DM}$. $\mathrm{KL}$ conducted the analysis and wrote the draft with key input from DM and ABG. $\mathrm{DM}$ and $\mathrm{ABG}$ provided edits and feedback. All authors revised and approved the manuscript before submission.

Funding $\mathrm{KL}$ is funded by the Roger and Sue Whorrod PhD studentship. ABG is funded by SPECTRUM, a UK Prevention Research Partnership (UKPRP) Consortium (MR/S037519/1). UKPRP is an initiative funded by the UK Research and Innovation Councils, the Department of Health and Social Care (England) and the UK devolved administrations, and leading health research charities.

Disclaimer The opinions expressed are those of the authors alone. The funders had no role in study design, data collection, analysis, decision to publish or preparation of the manuscript. DM received no specific funding for this work.

Competing interests None declared.

Patient consent for publication Not required.

Provenance and peer review Not commissioned; externally peer reviewed.

Data availability statement Data are available in a public, open access repository. All data analysed for this study are in the public domain.

Supplemental material This content has been supplied by the author(s). It has not been vetted by BMJ Publishing Group Limited (BMJ) and may not have been peer-reviewed. Any opinions or recommendations discussed are solely those of the author(s) and are not endorsed by BMJ. BMJ disclaims all liability and responsibility arising from any reliance placed on the content. Where the content includes any translated material, BMJ does not warrant the accuracy and reliability of the translations (including but not limited to local regulations, clinical guidelines, terminology, drug names and drug dosages), and is not responsible for any error and/or omissions arising from translation and adaptation or otherwise.

Open access This is an open access article distributed in accordance with the Creative Commons Attribution 4.0 Unported (CC BY 4.0) license, which permits others to copy, redistribute, remix, transform and build upon this work for any purpose, provided the original work is properly cited, a link to the licence is given, and indication of whether changes were made. See: https://creativecommons.org/ licenses/by/4.0/.

ORCID iD

Kathrin Lauber http://orcid.org/0000-0003-0073-3004

\section{REFERENCES}

1 Afshin A, Sur PJ, Fay KA. Health effects of dietary risks in 195 countries, 1990-2017: a systematic analysis for the global burden of disease study 2017. Lancet 2019;393:1958-72.

2 Murray CJL, Aravkin AY, Zheng P. Global burden of 87 risk factors in 204 countries and territories, 1990-2019: a systematic analysis for the global burden of disease study 2019. Lancet 2020;396:1223-49.

3 World Health Organization. Global action plan for the prevention and control of NCDs 2013-2020. Geneva: World Health Organization, 2013.

4 Hyseni L, Elliot-Green A, Lloyd-Williams F, et al. Systematic review of dietary salt reduction policies: evidence for an effectiveness hierarchy? PLoS One 2017;12:e0177535.

5 Sing F, Mackay S, Culpin A, et al. Food advertising to children in New Zealand: a critical review of the performance of a selfregulatory complaints system using a public health law framework. Nutrients 2020;12:1278.

6 Landwehr SC, Hartmann M. Industry self-regulation of food advertisement to children: compliance versus effectiveness of the EU Pledge. Food Policy 2020;91:101833.

7 Parker LA, Zaragoza GA, Hernández-Aguado I. Promoting population health with public-private partnerships: where's the evidence? BMC Public Health 2019;19:1438.
8 Théodore FL, Tolentino-Mayo L, Hernández-Zenil E, et al. Pitfalls of the self-regulation of advertisements directed at children on Mexican television. Pediatr Obes 2017;12:312-9.

9 Huizinga O, Kruse M. Food industry self-regulation scheme "EU Pledge" cannot prevent the marketing of unhealthy foods to children. Obes Med 2016;1:24-8.

10 Knai C, Petticrew M, Durand MA, et al. Has a public-private partnership resulted in action on healthier diets in England? an analysis of the public health responsibility deal food pledges. Food Policy 2015;54:1-10.

11 Goiana-da-Silva F, Severo M, Cruz E Silva D, et al. Projected impact of the Portuguese sugar-sweetened beverage tax on obesity incidence across different age groups: amodelling study. PLoS Med 2020;17:e1003036.

12 Cobiac LJ, Vos T, Veerman JL. Cost-Effectiveness of interventions to reduce dietary salt intake. Heart 2010;96:1920-5.

13 WHO Regional Office for Europe. Evaluating implementation of the who set of recommendations on the marketing of foods and nonalcoholic beverages to children. Progress, challenges and guidance for next steps in the WHO European region. Copenhagen: WHO Regional Office for Europe, 2018.

14 Bandy LK, Scarborough P, Harrington RA, et al. The sugar content of foods in the UK by category and company: a repeated crosssectional study, 2015-2018. PLoS Med 2021;18:e1003647.

15 Essman M, Taillie LS, Frank T, et al. Taxed and untaxed beverage intake by South African young adults after a national sugarsweetened beverage tax: a before-and-after study. PLoS Med 2021;18:e1003574.

16 Erzse A, Christofides N, Stacey N, et al. Availability and advertising of sugar sweetened beverages in South African public primary schools following a voluntary pledge by a major beverage company: a mixed methods study. Glob Health Action 2021;14:1898130.

17 Swinburn BA, Kraak VI, Allender S, et al. The global syndemic of obesity, undernutrition, and climate change: the Lancet commission report. Lancet 2019;393:791-846.

18 Clark H, Coll-Seck AM, Banerjee A, et al. A future for the world's children? A WHO-UNICEF-Lancet Commission. Lancet 2020;395:605-58.

19 Marten R, Kadandale S, Butler J, et al. Sugar, tobacco, and alcohol taxes to achieve the SDGs. Lancet 2018;391:2400-1.

20 Cathaoir K O, Hartlev M, Brassart Olsen C. Global health law and obesity: towards a complementary approach of public health and human rights law. In: Burci GL, Toebes BCA, eds. Research Handbook on global health law. Northampton, MA: Edward Elgar Publishing, 2018.

21 Latour B. Science in action: how to follow scientists and engineers through Society. Cambridge, MA: Harvard University Press, 1988.

22 Smith K. Beyond evidence-based policy in public health: the interplay of ideas. London: Palgrave Macmillan UK, London, 2013.

23 Evidence Use in Health Policy Making. An international public policy perspective. Cham: Palgrave Macmillan, 2018.

24 Cairney P, Yamazaki M. A comparison of tobacco policy in the UK and Japan: if the scientific evidence is identical, why is there a major difference in policy? Journal of Comparative Policy Analysis: Research and Practice 2018;20:253-68.

25 Barnes A, Parkhurst J. Can global health policy be depoliticized? A critique of global calls for evidence-based policy. The Handbook of Global Health Policy, 2014: 157-73.

26 WHO Regional Office for Europe. Evidence-Informed policymaking, 2021. Available: https://www.euro.who.int/en/data-andevidence/evidence-informed-policy-making/evidence-informedpolicy-making [Accessed 12 Jul 2021].

27 Hanefeld J, Walt G. Knowledge and networks - key sources of power in global health: comment on "Knowledge, moral claims and the exercise of power in global health". Int J Health Policy Manag 2015;4:119-21.

28 Vandenbrink D, Pauzé E, Potvin Kent M. Strategies used by the Canadian food and beverage industry to influence food and nutrition policies. Int J Behav Nutr Phys Act 2020;17:3.

29 Crosbie E, Carriedo A, Schmidt L. Hollow threats: transnational food and beverage companies' use of international agreements to fight front-of-pack nutrition labeling in Mexico and beyond. Int $J$ Health Policy Manag 2020

30 Mialon M, Crosbie E, Sacks G. Mapping of food industry strategies to influence public health policy, research and practice in South Africa. Int J Public Health 2020;65:1027-36.

31 Ojeda E, Torres C, Carriedo Ángela, et al. The influence of the sugar-sweetened beverage industry on public policies in Mexico. Int J Public Health 2020;65:1037-44. 
32 Serodio P, Ruskin G, McKee M, et al. Evaluating Coca-Cola's attempts to influence public health 'in their own words': analysis of Coca-Cola emails with public health academics leading the Global Energy Balance Network. Public Health Nutr 2020;23:2647-53.

33 Steele S, Ruskin G, Stuckler D. Pushing partnerships: corporate influence on research and policy via the International Life Sciences Institute. Public Health Nutr 2020;23:2032-40.

34 Lauber K, Rutter H, Gilmore AB. Big Food and the World Health Organization: a qualitative study of industry attempts to influence global-level non-communicable disease policy. BMJ Glob Health 2021;6:e005216.

35 Cullerton K, Donnet T, Lee A, et al. Playing the policy game: a review of the barriers to and enablers of nutrition policy change. Public Health Nutr 2016;19:2643-53.

36 Baker P, Gill T, Friel S, et al. Generating political priority for regulatory interventions targeting obesity prevention: an Australian case study. Soc Sci Med 2017;177:141-9.

37 Savell E, Gilmore AB, Fooks G. How does the tobacco industry attempt to influence marketing regulations? A systematic review. PLoS One 2014;9:e87389.

38 Smith KE, Savell E, Gilmore AB. What is known about tobacco industry efforts to influence tobacco tax? A systematic review of empirical studies. Tob Control 2013;22:e1.

39 Amul GGH, Tan GPP, van der Eijk Y. A systematic review of tobacco industry tactics in Southeast Asia: lessons for other low- and middle-income regions. Int J Health Policy Manag 2020. doi:10.34172/ijhpm.2020.97. [Epub ahead of print: 21 Jun 2020].

40 Ulucanlar S, Fooks GJ, Gilmore AB. The Policy Dystopia Model: an interpretive analysis of tobacco industry political activity. PLoS Med 2016;13:e1002125.

41 Nestle M. Unsavory truth: how food companies skew the science of what we eat. New York, NY: Basic Books, 2018.

42 Steele S, Ruskin G, Sarcevic L, et al. Are industry-funded charities promoting "advocacy-led studies" or "evidence-based science"?: A case study of the International Life Sciences Institute. Global Health 2019;15:36.

43 Sacks G, Swinburn BA, Cameron AJ, et al. How food companies influence evidence and opinion - straight from the horse's mouth. Crit Public Health 2018;28:253-6.

44 Gómez EJ. Coca-Cola's political and policy influence in Mexico: understanding the role of institutions, interests and divided society. Health Policy Plan 2019;34:520-8.

45 Mialon M, Gaitan Charry DA, Cediel G, et al. "The architecture of the state was transformed in favour of the interests of companies": corporate political activity of the food industry in Colombia. Global Health 2020;16:97.

46 Petticrew M, Maani Hessari N, Knai C, et al. How alcohol industry organisations mislead the public about alcohol and cancer. Drug Alcohol Rev 2018;37:293-303.

47 Petticrew M, Maani Hessari N, Knai C, et al. The strategies of alcohol industry SAPROs: inaccurate information, misleading language and the use of confounders to downplay and misrepresent the risk of cancer. Drug Alcohol Rev 2018;37:313-5.

48 Bertscher A, London L, Orgill M. Unpacking policy formulation and industry influence: the case of the draft control of marketing of alcoholic beverages bill in South Africa. Health Policy Plan 2018;33:786-800.

49 Savell E, Fooks G, Gilmore AB. How does the alcohol industry attempt to influence marketing regulations? A systematic review. Addiction 2016;111:18-32.

50 Legg T, Hatchard J, Gilmore AB. The science for profit model - how and why corporations influence science and the use of science in policy and practice. PLoS One 2021;16:e0253272.

51 Fabbri A, Holland TJ, Bero LA. Food industry sponsorship of academic research: investigating commercial bias in the research agenda. Public Health Nutr 2018;21:3422-30.

52 Fabbri A, Chartres N, Scrinis G, et al. Study sponsorship and the nutrition research agenda: analysis of randomized controlled trials included in systematic reviews of nutrition interventions to address obesity. Public Health Nutr 2017;20:1306-13.

53 Bes-Rastrollo M, Schulze MB, Ruiz-Canela M, et al. Financial conflicts of interest and reporting bias regarding the association between sugar-sweetened beverages and weight gain: a systematic review of systematic reviews. PLoS Med 2014;10:e1001578.

54 Schillinger D, Tran J, Mangurian C, et al. Do sugar-sweetened beverages cause obesity and diabetes? Industry and the manufacture of scientific controversy. Ann Intern Med 2016;165:895-7.

55 Sacks G, Riesenberg D, Mialon M, et al. The characteristics and extent of food industry involvement in peer-reviewed research articles from 10 leading nutrition-related journals in 2018. PLOS One 2020;15:e0243144.

56 Hatchard JL, Fooks GJ, Evans-Reeves KA, et al. A critical evaluation of the volume, relevance and quality of evidence submitted by the tobacco industry to oppose standardised packaging of tobacco products. BMJ Open 2014;4:e003757

57 Lencucha R, de Lima Pontes C. The context and quality of evidence used by tobacco interests to oppose ANVISA's 2012 regulations in Brazil. Glob Public Health 2018;13:1204-15.

58 Ulucanlar S, Fooks GJ, Hatchard JL, et al. Representation and misrepresentation of scientific evidence in contemporary tobacco regulation: a review of tobacco industry submissions to the UK government consultation on standardised packaging. PLoS Med 2014;11:e1001629.

59 Cullen D, Smith K, Collin J. 'Half-cut' science: a qualitative examination of alcohol industry actors' use of peer-reviewed evidence in policy submissions on Minimum Unit Pricing. Evid Policy 2018. doi:10.1332/174426417X15071939491726

60 McCambridge J, Hawkins B, Holden C. Industry use of evidence to influence alcohol policy: a case study of submissions to the 2008 Scottish government consultation. PLoS Med 2013;10:e1001431.

61 Stafford J, Kypri K, Pettigrew S. Industry actor use of research evidence: critical analysis of Australian alcohol policy submissions. J Stud Alcohol Drugs 2020;81:710-8.

62 Fooks GJ, Williams S, Box G, et al. Corporations' use and misuse of evidence to influence health policy: a case study of sugarsweetened beverage taxation. Global Health 2019;15:56.

63 Lauber K, Ralston R, Mialon M, et al. Non-Communicable disease governance in the era of the sustainable development goals: a qualitative analysis of food industry framing in WHO consultations. Global Health 2020;16:76.

64 Abdool Karim S, Kruger P, Hofman K. Industry strategies in the parliamentary process of adopting a sugar-sweetened beverage tax in South Africa: a systematic mapping. Global Health 2020;16:116.

65 Proctor RN. Agnotology: A Missing Term to Describe the Cultural Production of Ignorance (and Its Study). In: Proctor RN, Schiebinger L, eds. Agnotology: the making and Unmaking of ignorance. Stanford, CA: Stanford University Press, 2008.

66 WHO Independent High-level Commission on NCDs. Web-based consultation (10-16 May 2018). Geneva: World Health Organization, 2018. Available: https://www.who.int/ncds/governance/high-levelcommission/web-based-consultation-may2018/ [Accessed 31 Mar 2020].

67 World Health Organization. Montevideo roadmap 2018-2030 on NCDS as a sustainable development priority. Geneva: World Health Organization, 2017

68 World Health Organization. Tackling NCDs: 'Best buys' and other recommended interventions for the prevention and control of noncommunicable diseases. Geneva: World Health Organization, 2017.

69 World Health Organization. Shanghai declaration on promoting health in the 2030 agenda for sustainable development. Geneva: World Health Organization, 2016.

70 Alianza Latinoamericana de Asociaciones de la Industria de Alimentos y Bebidas. Comments on the Montevideo roadmap 2018-2030 on NCDs as a sustainable development priority, 2017

71 Alianza Latinoamericana de Asociaciones de la Industria de Alimentos y Bebidas. Comments on the draft first report of the WHO independent high-level commission on non-communicable diseases, 2018

72 Asociación Nacional de Fabricantes de Alimentos y Bebidas. Comments on the draft first report of the WHO independent highlevel commission on non-communicable diseases, 2018

73 Cámara de la Industria de Alimentos de Colombia. Comments on the draft first report of the WHO independent high-level commission on non-communicable diseases, 2018

74 Consejo Mexicano de la Industria de Productos de Consumo. Comments on the montevideo roadmap 2018-2030 on NCDS as a sustainable development priority, 2017

75 Consejo Mexicano de la Industria de Productos de Consumo. Comments on the draft first report of the WHO independent highlevel commission on non-communicable diseases, 2018

76 Alimentos y Bebidas de Chile. Comments on the draft first report of the WHO independent high-level commission on noncommunicable diseases, 2018

77 ATLAS.ti for Mac, Version 9.0.5 [program]. Berlin: ATLAS.ti Scientific Software783 Development GmbH, Released 2020. Available: https://atlasti.com

78 Evans-Reeves KA, Hatchard JL, Gilmore AB. 'It will harm business and increase illicit trade': an evaluation of the relevance, quality and transparency of evidence submitted by transnational tobacco 
companies to the UK consultation on standardised packaging 2012. Tob Control 2015;24:e168-77.

79 Euromonitor International. Packaged food statistics 2021.

80 Euromonitor International. Soft drinks statistics 2021.

81 Flourish, 2021Kiln Enterprises. Available: https://flourish.studio/

82 Federalimentare. Comments on the draft first report of the WHO independent high-level commission on non-communicable diseases, 2018

83 International Food and Beverage Alliance. Comments on the zero draft Shanghai declaration on health promotion in the 2030 agenda for sustainable development, 2016

84 Consumer Brands Association. Bold new agenda, new name: GMA to relaunch as Consumer Brands Association ${ }^{\mathrm{TM}}$ in 2020, 2019. Available: https://web.archive.org/web/20200131113644/https:// consumerbrandsassociation.org/press-releases/bold-new-agendanew-name-gma-to-relaunch-as-consumer-brands-association-in2020/ [Accessed 31 Jan 2020].

85 Germany FF. Philipp Hengstenberg is president of new "Food Federation Germany", 2019. Available: https://www. lebensmittelverband.de/en/news/20190509-philipp-hengstenbergis-president-of-new-food-federation-germany [Accessed 6 Mar 2021].

$86 \mathrm{Ha} \mathrm{V}$, Cozma Al, Choo VLW, et al. Do fructose-containing sugars lead to adverse health consequences? Results of recent systematic reviews and meta-analyses. Adv Nutr 2015;6:504S-11.

87 Kahn R, Sievenpiper JL, Sugar D. Dietary sugar and body weight: have we reached a crisis in the epidemic of obesity and diabetes? Diabetes Care 2014;37:957-62.

88 Rippe JM, Angelopoulos TJ. Added sugars and risk factors for obesity, diabetes and heart disease. Int J Obes 2016;40 Suppl 1:S22-7.

89 Noronha JC, Choo V, Blanco Mejia S. Liquid calories from sugars do not increase body weight more than solid calories: a systematic review and meta-analysis of controlled feeding trials. Faseb $J$ 2016;30:906.6-06.6.

90 Gadah NS, Kyle LA, Smith JE, et al. No difference in compensation for sugar in a drink versus sugar in semi-solid and solid foods. Physiol Behav 2016;156:35-42.

91 Wittekind A, Walton J. Worldwide trends in dietary sugars intake. Nutr Res Rev 2014:27:330-45.

92 Hanks A, Wansink B, Just D, et al. From coke to Coors: a field study of a fat tax and its unintended consequences. J Nutr Educ Behav 2013;45:S40.

93 Kees J, Fitzgerald MP. Who uses facts up front? A baseline examination of who is using standardized Front-of-Package nutrition disclosures. J Consum Aff 2016;50:458-70.

94 Kees J, Royne MB, Cho Y-NA. Regulating Front-of-Package nutrition information disclosures: a test of industry self-regulation vs. other popular options. J Consum Aff 2014;48:147-74.

95 Borys J-M, Valdeyron L, Levy E, et al. EPODE - a model for reducing the incidence of obesity and weight-related comorbidities. Eur Endocrinol 2013;9:116-20.

96 Smith Edge M, Toner C, Kapsak WR, et al. The impact of variations in a fact-based front-of-package nutrition labeling system on consumer comprehension. J Acad Nutr Diet 2014;114:843-54.

97 Van Koperen TM, Jebb SA, Summerbell CD, et al. Characterizing the EPODE logic model: unravelling the past and Informing the future. Obes Rev 2013;14:162-70.

98 Quirmbach D, Cornelsen L, Jebb SA, et al. Effect of increasing the price of sugar-sweetened beverages on alcoholic beverage purchases: an economic analysis of sales data. $J$ Epidemiol Community Health 2018;72:324-30.

99 Economics O. The Economic Impact of Philadelphia's Beverage Tax. Oxford: Oxford Economics, 2017.

100 International Tax and Investment Center, Oxford Economics. The impact of selective food and non-alcoholic beverage taxes. Oxford: Oxford Economics, 2016.

101 Dobbs R, Sawers C, Thompson F. Overcoming obesity: an initial economic analysis. New York: McKinsey Global Institute, 2014.

102 Bes-Rastrollo M, Sayon-Orea C, Ruiz-Canela M, et al. Impact of sugars and sugar taxation on body weight control: a comprehensive literature review. Obesity 2016;24:1410-26.

103 Colchero MA, Popkin BM, Rivera JA, et al. Beverage purchases from stores in Mexico under the excise tax on sugar sweetened beverages: observational study. BMJ 2016;352:h6704.

104 Silver LD, Ng SW, Ryan-Ibarra S, et al. Changes in prices, sales, consumer spending, and beverage consumption one year after a tax on sugar-sweetened beverages in Berkeley, California, US: a before-and-after study. PLoS Med 2017;14:e1002283.
105 Trumbo PR, Rivers CR. Systematic review of the evidence for an association between sugar-sweetened beverage consumption and risk of obesity. Nutr Rev 2014;72:566-74.

106 International Council of Beverages Associations. Comments on the WHO discussion paper on the draft updated Appendix 3 of the WHO global NCD action plan 2013-2020 2016.

107 World Health Organization. Guideline: sugars intake for adults and children. Geneva: World Health Organization, 2015.

108 EPODE International Network. Partners, 2016. Available: https://web.archive.org/web/20160323231215/http://epodeinternational-network.com/support/partners [Accessed 23 Mar 2016].

109 Niebylski ML, Redburn KA, Duhaney T, et al. Healthy food subsidies and unhealthy food taxation: a systematic review of the evidence. Nutrition 2015;31:787-95.

110 Cabrera Escobar MA, Veerman JL, Tollman SM, et al. Evidence that a tax on sugar sweetened beverages reduces the obesity rate: a meta-analysis. BMC Public Health 2013;13:1072.

111 Nakhimovsky SS, Feigl AB, Avila C, et al. Taxes on sugarsweetened beverages to reduce overweight and obesity in middle-income countries: a systematic review. PLoS One 2016;11:e0163358.

112 Pell D, Mytton O, Penney TL, et al. Changes in soft drinks purchased by British households associated with the UK soft drinks industry levy: controlled interrupted time series analysis. BMJ 2021;372:n254.

113 Teng AM, Jones AC, Mizdrak A, et al. Impact of sugar-sweetened beverage taxes on purchases and dietary intake: systematic review and meta-analysis. Obes Rev 2019;20:1187-204.

114 Te Morenga L, Mallard S, Mann J. Dietary sugars and body weight: systematic review and meta-analyses of randomised controlled trials and cohort studies. BMJ 2012;346:e7492.

115 Malik VS, Pan A, Willett WC, et al. Sugar-Sweetened beverages and weight gain in children and adults: a systematic review and meta-analysis. Am J Clin Nutr 2013;98:1084-102.

116 Ebbeling CB, Feldman HA, Chomitz VR, et al. A randomized trial of sugar-sweetened beverages and adolescent body weight. $N$ Engl $J$ Med 2012;367:1407-16

117 Frantsve-Hawley J, Bader JD, Welsh JA, et al. A systematic review of the association between consumption of sugar-containing beverages and excess weight gain among children under age 12. $J$ Public Health Dent 2017;77 Suppl 1:S43-66.

118 Mounsey S, Veerman L, Jan S, et al. The macroeconomic impacts of diet-related fiscal policy for NCD prevention: a systematic review. Econ Hum Biol 2020;37:100854.

119 Guerrero-López CM, Molina M, Colchero MA. Employment changes associated with the introduction of taxes on sugarsweetened beverages and nonessential energy-dense food in Mexico. Prev Med 2017:105S:S43-9.

120 Lawman HG, Bleich SN, Yan J, et al. Unemployment claims in Philadelphia one year after implementation of the sweetened beverage Tax. PLoS One 2019;14:e0213218.

121 Powell LM, Wada R, Persky JJ, et al. Employment impact of sugarsweetened beverage taxes. Am J Public Health 2014;104:672-7.

122 Taillie LS, Reyes M, Colchero MA, et al. An evaluation of Chile's law of food labeling and advertising on sugar-sweetened beverage purchases from 2015 to 2017: a before-and-after study. PLoS Med 2020;17:e1003015.

123 Correa T, Fierro C, Reyes M, et al. "Responses to the Chilean law of food labeling and advertising: exploring knowledge, perceptions and behaviors of mothers of young children". Int J Behav Nutr Phys Act 2019;16:21.

124 Paraje G, Colchero A, Wlasiuk JM, et al. The effects of the Chilean food policy package on aggregate employment and real wages. Food Policy 2021;100:102016.

125 León-Flández K, Rico-Gómez A, Moya-Geromin M Á, et al. Evaluation of compliance with the Spanish code of self-regulation of food and drinks advertising directed at children under the age of 12 years in Spain, 2012. Public Health 2017;150:121-9.

126 Vandevijvere S, Soupen A, Swinburn B. Unhealthy food advertising directed to children on new Zealand television: extent, nature, impact and policy implications. Public Health Nutr 2017;20:3029-40.

127 Potvin Kent M, Smith JR, Pauzé E, et al. The effectiveness of the food and beverage industry's self-established uniform nutrition criteria at improving the healthfulness of food advertising viewed by Canadian children on television. Int J Behav Nutr Phys Act 2018;15:57.

128 Galbraith-Emami S, Lobstein T. The impact of initiatives to limit the advertising of food and beverage products to children: a systematic review. Obes Rev 2013;14:960-74. 
129 Rajamohan S, Meaney K, et al. Development of a responsible policy index to improve statutory and self-regulatory policies that protect children's diet and health in the America's region. Int $J$ Environ Res Public Health 2020;17:495.

130 Grundy Q, Dunn AG, Bero L. Improving researchers' conflict of interest declarations. BMJ 2020;368:m422.

131 Tobacco Tactics. Oxford Economics, 2020University of Bath. Available: https://tobaccotactics.org/wiki/oxford-economics/ [Accessed 2 Jan 2021].

132 Campbell N, Mialon M, Reilly K. How are frames generated? Insights from the industry lobby against the sugar Tax in Ireland. Soc Sci Med 2020;113215.

133 Hatchard JL, Evans-Reeves KA, Ulucanlar S, et al. How do corporations use evidence in public health policy making? The case of standardised tobacco packaging. Lancet 2013;382:S42.
134 Knai C, Petticrew M, Capewell S, et al. The case for developing a cohesive systems approach to research across unhealthy commodity industries. BMJ Glob Health 2021;6:e003543.

135 Moodie AR. What public health practitioners need to know about unhealthy industry tactics. Am J Public Health 2017;107:1047-9.

136 Capewell S, Lloyd-Williams F. The role of the food industry in health: lessons from tobacco? Br Med Bull 2018;125:131-43.

137 Brownell KD, Warner KE. The perils of ignoring history: big tobacco played dirty and millions died. How similar is big food? Milbank $Q$ 2009;87:259-94.

138 World Health Organization. WHO Framework Convention on Tobacco Control. Geneva: World Health Organization, 2003.

139 Whitaker K, Webb D, Linou N. Commercial influence in control of non-communicable diseases. BMJ 2018;360:k110. 